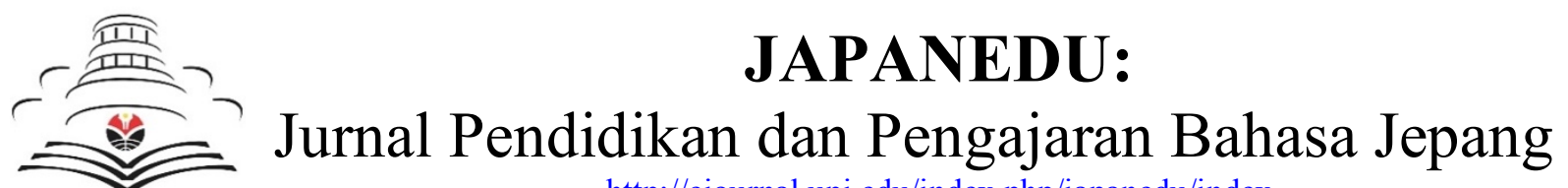

\title{
The Perception of Japanese Language Education Students About Microteaching
}

\author{
Desak Made Sri Mardani, Ni Nyoman Padmadewi \\ Japanese Language Department, Universitas Pendidikan Ganesha, Jalan Ahmad Yani, Singaraja, Indonesia \\ desak.mardani@undiksha.ac.id.,nym.padmadewi@undiksha.ac.id
}

\begin{abstract}
Microteaching is one of the subject matters to prepare student teachers. Many publications confirm the function and importance of microteaching in improving the student teachers' teaching skills. However, publication on the perception of Japanese Language Education students about microteaching is still limited, despite its importance in guiding the students for better improvement. This study aimed at analyzing the students' perception on the implementation of microteaching at the Japanese Language Education in a university in Bali on 2018. This study used qualitative research, and the data collected by questionnaire and interview. The results of the analysis showed that holistically, the students have postive perception and microteaching is perceived as very useful to improve the student teachers' teaching skills. The instrumens used are not only relevant to assess the progress and the achievement of the student teachers but also can function as guideline for students on what to do in improving the teaching skills.
\end{abstract}

K E Y W O R D S

Microteaching; Students' perception; Japanese Language Education.

First received: 20 August $2020 \quad$ Final proof accepted: 30 November 2020

Available online: 31 December 2020

\section{PENDAHULUAN}

Telah menjadi kebijakan nasional di Indonesia bahwa Kurikulum 2013 (K-13) mulai diberlakukan di beberapa sekolah sejak tahun 2013 dan mulai digunakan secara serentak di seluruh Indonesia. Pasal 4 Permendikbud No 160/2014 tentang pemberlakuan Kurikulum 2006 dan Kurikulum 2013 menyatakan bahwa Satuan Pendidikan Dasar dan Pendidikan Menengah dapat melaksanakan kurikulum 2006 paling lama sampai dengan tahun pelajaran 2019/2020.

Hasil observasi di sekolah-sekolah negeri di Bali, status bahasa Jepang tidak dimasukkan sebagai mata pelajaran wajib tetapi dimasukkan sebagai peminatan yang dilakukan di SMA/K. Memiliki status sebagai peminatan, guru bahasa Jepang harus mampu mengajarkan bahasa Jepang secara komunikatif agar setelah tamat siswa mampu menggunakan bahasa Jepang dalam hidup mereka. Sedangkan dalam 
Kurikulum 2006, bahasa Jepang adalah mata pelajaran bahasa asing dan proses pembelajarannya dilakukan lebih bersifat formal dan teoritis. Dengan demikian, dengan statusnya sebagai peminatan, pembelajaran bahasa Jepang harus disesuaikan, dan guru pengajar harus memiliki kompetensi pembelajaran yang menghasilkan siswa untuk mampu menggunakan bahasa Jepang dalam konteks kehidupan nyata (tidak hanya bersifat teoritis dan struktural) yang bisa dipakai sebagai bekal dan dasar untuk studi lanjut maupun untuk bekerja.

Berdasarkan hasil observasi yang dilakukan di sekolah tempat mahasiswa melakukan Praktek Pengalaman Lapangan (PPL) di kota Singaraja, dapat dinyatakan bahwa proses pembelajaran masih bersifat konvensional dan kurang kontekstual. Dengan kata lain, mahasiswa calon guru masih sangat tergantung pada buku teks/lembar kerja siswa (LKS) dan belum mampu secara inovatif melaksanakan pembelajaran yang berpusat pada siswa (students centred approach). Oleh sebab itu perlu upaya kongkret untuk meningkatkan keterampilan mahasiswa calon guru agar mampu mengajar bahasa Jepang secara lebih inovatif, menarik dan mampu menghasilkan siswa yang mampu berbahasa Jepang, seperti yang dinyatakan dalam standar proses Kurikulum 2013 (Permendikbud no 81a tahun 2013).

Ada tiga komponen yang dicakup dalam Standar Proses Kurikulum 2013 yaitu yang berkenaan dengan perencanaan pembelajaran, dan pelaksanaan pembelajaran yang harus menggunakan pendekatan saintifik (yang diatur kembali dalam Permendikbud No 103/2014 tentang pembelajaran pada pendidikan dasar dan pendidikan menengah), dan tentang penilaian (yang diatur dalam Permendikbud No 104 tentang penilaian hasil belajar oleh pendidik pada pendidikan dasar dan pendidikan menengah). Dengan adanya aturan-aturan baru tersebut, pihak Jurusan Pendidikan Bahasa Jepang harus melakukan upaya agar lulusannya memiliki kompetensi untuk mampu menjalankan kebijakan yang dinyatakan dalam peraturan Kementrian Pendidikan dan Kebudayaan Republik Indonesia. Salah satu upaya yang dilakukan adalah mencermati dan memberdayakan mata kuliah Microteaching sebagai muara keterampilan pedagogik dan persyaratan untuk melakukan praktek mengajar di sekolah.
Centre for Teaching and Learning, Harvard Univeristy menyatakan bahwa microteaching adalah praktek pembelajaran yang memiliki tujuan untuk memberikan instruktur (calon guru) rasa percaya diri, dukungan, dan masukan dengan memberikan kesempatan kepada mereka mempraktekkan bagian demi bagian dari apa yang telah direncanakan bersama teman mereka. Idealnya sesi microteaching dimulai sebelum hari pertama perkuliahan dimulai, direkam untuk bisa direviu secara individual bersama dosen yang berpengalaman. Microteaching merupakan cara yang cepat, efisien, menarik dan terbukti mampu membantu calon guru mulai mengajar dengan awal yang baik. "Microteaching is organized practice teaching. The goal is to give instructors confidence, support, and feedback by letting them try out among friends and colleagues a short slice of what they plan to do with their students. Ideally, microteaching sessions take place before the first day of class, and are videotaped for review individually with an experienced teaching consultant. Microteaching is a quick, efficient, proven, and fun way to help teachers get off to a strong start" (http://boxcentre.harvard.edu).

Konsep microteaching juga dijelaskan oleh University of Guelph dari sisi pelaksanaannya di kelas (www.tss.uoguelph.ca). Dinyatakan bahwa microteaching merupakan bentuk latihan pengajaran dimana kelompok kecil mahasiswa saling merekam dan mengobservasi praktek pembelajaran satu sama lain, memberikan masukan, terlibat dalam diskusi dengan tujuan untuk meningkatkan kemampuan mereka dalam melaksanakan pembelajaran. Dalam microteaching, mahasiswa diberikan kesempatan untuk mempraktekkan keterampilan instruksional dalam lingkungan pembelajaran yang berpusat pada siswa serta memiliki tujuan untuk memperkuat pendekatan mahasiswa tentang pembelajaran, mengidentifikasi kekuatan dan kelebihan mahasiswa melalui refleksi dan diskusi, memperkaya pemhaman dan keterampilan mahasiswa tentang berbagai gaya mengajar yang efektif dan meningkatkan kemampuan mahasiswa untuk memberikan dan menerima masukan yang efektif. Microteaching merupakan teknik latihan untuk belajar menjadi guru (Bello \& Ayelaagbe, 2015); latihan untuk menjadi guru baik untuk calon guru maupun untuk guru dalam jabatan (Ghafoor dkk., 2012).

Berdasarkan kutipan tersebut, inti mata kuliah microteaching adalah mempraktekkan bagian demi bagian keterampilan mengajar secara mikro, berulang, dan direviu oleh teman 
sekelas dan dosen pengampu mata kuliah. Dengan demikian ada beberapa keterampilan dasar yang dipilah untuk dilatih dan dipraktekkan secara terpisah agar nanti keterampilan-keterampilan dasar yang sudah terlatih bisa membentuk kompetensi pedagogik yang memadai.

Menurut PACE (Partnership for Advance Clinical Education), keterampilan dasar dalam microteaching dikelompokkan menjadi 6 keterampilan yaitu 1) Set induction (apersepsi), 2) planning (membuat perencanaan), 3) presentation (keterampilan melakukan presentasi), 4) Pupil presentation (presentasi siswa), 5) penggunaan media Audio Visual, dan 6) Closure (penutup). Keterampilan tersebut dilatih di tiap-tiap sesi untuk pertemuan sekitar 5-10 menit untuk di kelompok terdiri dari sekitar 4-10 orang (chs.uonbi.ac.ke).

Pendapat lain tentang keterampilan dasar microteaching di Jiaxing University China, terdiri dari: 1) teknik memberikan reinforcement, 2) memvariasikan situasi stimulus, 3) keterampilan presentasi, 4) ilustrasi dan penggunaan contoh, dan 5) keterampilan menggali pertanyaan siswa (Ping, 2013). Sedangkan Ghanaguru, Nair dan Yong (2013) menyatakan microteaching sebagai upaya untuk menekankan pada praktek pembelajaran yang memungkinkan mahasiswa calon guru untuk menguji keterampilan pedagogisnya yang diasimilasikan dalam konteks pembelajaran.

Berdasarkan kajian informasi di atas, dapat dinyatakan bahwa semua konsep tersebut mengacu pada muara tujuan yang sama bahwa microteaching merupakan mata kulian untuk melatih keterampilan mengajar mahasiswa dengan mempraktekkan keterampilanketerampilan dasar pedagogik dalam kelompok kecil kemudian mendiskusikannya untuk perbaikan. Semua keterampilan dasar yang dilatih pada dasarnya mengacu pada tujuan yang sama yaitu terampil dalam mengajar. Dengan kata lain siklus pembelajaran microteaching seperti dipaparkan di atas menekankan pada mempraktekkan keterampilan dasar microteaching secara mikro, yang kemudian diberikan masukan dari berbagai pihak sebelum kemudian diadakan revisi perbaikan sebelum dipraktekkan kembali.

Banyak penelitian telah dilakukan yang menganalisis manfaat dan pentingnya mata kuliah microteaching dalam pembentukan keterampilan guru mengajar (Fernandez, 2005; Kpanja, 2001; Kumar, 2016; Anthonia, 2014), tetapi persepsi mahasiswa Pendidikan Bahasa Jepang terhadap pelaksanaan pembelajaran microteaching belum banyak dipublikasikan. Penelitian terkait persepsi pembelajaran microteaching bahasa Jepang pernah dilakukan oleh Arismayanti, Padmadewi, dan Hermawan (2016), dimana diketahui bahwa dalam pembelajaran microteaching di Pendidikan Bahasa Jepang, Universitas Pendidikan Ganesha, mahasiswa tidak diberikan keterampilan mengajar yang mengarahkan pembelajaran sesuai dengan tuntutan kurikulum 2013. Penelitian ini kemudian menjadi salah satu dasar penelitian yang dilakukan oleh Padmadewi dan Mardani (2017).

Untuk merespon tuntutan Kurikulum 2013, upaya kongkret strategis yang bisa dilakukan adalah mereviu mata kuliah microteaching selaku muara dari semua mata kuliah keguruan sebagai wadah untuk menggodog calon guru, dan menyesuaikan model pelaksanaan pembelajarannya agar link dan match dengan kebutuhan di lapangan. Hal ini sudah dilakukan melalui penelitian Padmadewi dan Mardani (2017), dan penyesuaian materi microteaching sudah dilakukan sejak 2017. Dalam penelitian tersebut dihasilkan perangkat pembelajaran yang lengkap berupa: kontrak kuliah silabus, RPS (Rencana Program Semester), RTM (Rencana Tugas Mahasiswa), media pembelajaran (video dan powerpoint), buku ajar serta buku panduan pelaksanaan pembelajaran microteaching (di dalamnya terdapat rubrik penilaian pelaksanaan pembelajaran microteaching). Keseluruhan perangkat tersebut mengarahkan mahasiswa mempelajari dan melatih pembelajaran sesuai dengan tuntutan Kurikulum 2013. Perangkat microteaching ini juga diinsersi dengan keterampilan Abad 21 yaitu 4C (communication, collaboration, creativity dan critical thinking) (Trilling \& Fadel, 2009) serta disisipi oleh nilai-nilai karakter sehingga menjadi 5C. Penelitian tersebut sampai pada tahap penilaian perangkat pembelajaran oleh ahli dan pengajar mata kuliah microteaching. Tetapi belum dilakukan sebuah penelitian terkait tanggapan dan persepsi mahasiswa terhadap pelaksanaan microteaching yang telah disesuaikan tersebut. Oleh sebab itulah, penelitian ini bertujuan untuk meneliti dan menganalisis persepsi atau tanggapan mahasiswa tentang perkuliahan microteaching. Diharapkan hasil penelitian ini bisa dipakai sebagai bahan pertimbangan untuk penyempurnaan pelaksanaan pembelajaran 
microteaching di perguruan tinggi Bali, sebagai tahap lanjutan dari penelitian Padmadewi dan Mardani (2017) tentang penyesuaian pembelajaran microteaching. Hal ini sangat penting dilakukan karena selama ini pembelajaran bahasa Jepang di Indonesia lebih banyak mendapat bantuan dari negara Jepang, sedangkan peran dan fungsi bahasa Jepang dalam Kurikulum 2013 lebih sebagai mata pelajaran untuk peminatan. Oleh sebab itu mengetahui dan menganalisis persepsi mahasiswa tentang pembelajaran microteaching menjadi semakin penting.

\section{METODE PENELITIAN}

Secara keseluruhan penelitian ini menggunakan paradigma pendekatan embedded mixed method tipe (Creswell, 2009) dalam bentuk penelitian kualitatif dan didukung oleh analisis secara kuantitatif. Tetapi pada penelitian ini, persepsi mahasiswa dianalisis secara kualitatif melalui wawancara dan kuesiner dan didukung oleh analisis data melalui kuesioner. Populasi penelitian ini adalah mahasiswa dan dosen mata kuliah microteaching untuk Jurusan Pendidikan Bahasa Jepang untuk perguruan tinggi di Bali. Perguruan tinggi yang memiliki jurusan Pendidikan Bahasa Jepang di Bali adalah hanya Universitas Pendidikan Ganesha (Undiksha). Jumlah kelas yang mempelajari mata kuliah microteaching di Jurusan Pendidikan Bahasa Jepang adalah dua (2) kelas yang berjumlah 22 dan 26 orang mahasiswa. Untuk meningkatkan tingkat keterpercayaan terhadap data yang dikumpulkan, instrumen telah melewati uji ahli sebelum dipakai. Uji ahli dilakukan oleh pakar pendidikan yang memiliki keahlian dalam pembelajaran microteaching bahasa asing, dimana hasilnya dinyatakan bahwa instrumen tersebut sangat layak digunakan untuk memperoleh data terkait persepsi dan tanggapan mahasiswa tentang pelaksanaan pembelajaran microteaching. Data yang terkumpul lewat kuesioner dan wawancara dianalisis secara kualitatif dan juga didukung oleh perhitungan persentase.

\section{HASIL DAN PEMBAHASAN}

\section{Hasil Penelitian}

Untuk mendapatkan data yang menyeluruh, persepsi mahasiswa dianalisis dari berbagai aspek, yaitu persepsi tentang buku ajar yang digunakan dosen tanggapan terhadap proses perencanaan microteaching dan juga terhadap pelaksanaan microteaching secara umum.

Tabel 1 berikut ini adalah hasil analisis data yang ditunjukkan oleh mahasiswa mengenai tanggapan mereka terhadap buku ajar yang dipakai.

Tabel 1: Tanggapan mahasiswa dan dosen tentang buku microteaching.

\begin{tabular}{|c|c|c|c|}
\hline No & Pertanyaan & \multirow[t]{2}{*}{ Mean } & \multirow{2}{*}{$\begin{array}{l}\text { Standard } \\
\text { Deviation }\end{array}$} \\
\hline \multicolumn{2}{|c|}{ ASPEK ISI } & & \\
\hline 1 & $\begin{array}{l}\text { Buku microteaching } \\
\text { dan Panduannya } \\
\text { mudah dipahami }\end{array}$ & 4.48 & 0.505 \\
\hline 2 & $\begin{array}{l}\text { Buku microteaching } \\
\text { dan Panduannya } \\
\text { menggunakan } \\
\text { informasi yang } \\
\text { mudah dimengerti. }\end{array}$ & 4.25 & 0.438 \\
\hline 3 & $\begin{array}{l}\text { Instrumen penilaian } \\
\text { pada tiap-tiap } \\
\text { keterampilan dasar } \\
\text { relevan untuk } \\
\text { menilai tiap-tiap } \\
\text { keterampilan dasar }\end{array}$ & 4.85 & 0.357 \\
\hline 4 & $\begin{array}{l}\text { Semua instrumen } \\
\text { yang digunakan } \\
\text { sesuai dengan } \\
\text { tujuan keterampilan } \\
\text { dasar mengajar. }\end{array}$ & 4.79 & 0.410 \\
\hline 5 & $\begin{array}{l}\text { Buku microteaching } \\
\text { dan Panduan ini } \\
\text { membantu } \\
\text { mahasiswa untuk } \\
\text { memahami } \\
\text { pelajaran } \\
\text { microteaching dengan } \\
\text { lebih cepat. }\end{array}$ & 4.54 & 0.504 \\
\hline 6 & $\begin{array}{l}\text { Langkah-langkah } \\
\text { penggunaan tahapan } \\
\text { melaksanakan } \\
\text { microteaching jelas. }\end{array}$ & 4.71 & 0.459 \\
\hline 7 & $\begin{array}{l}\text { Instrumen yang } \\
\text { dibutuhkan dalam } \\
\text { pembelajaran } \\
\text { microteaching } \\
\text { lengkap. }\end{array}$ & 4.75 & 0.438 \\
\hline 8 & $\begin{array}{l}\text { Instrumen yang } \\
\text { digunakan }\end{array}$ & 4.29 & 0.459 \\
\hline
\end{tabular}




\begin{tabular}{|c|c|c|c|}
\hline & $\begin{array}{l}\text { memberikan } \\
\text { kesempatan pada } \\
\text { mahasiswa untuk } \\
\text { menilai diri sendiri } \\
\text { dan sejawat. }\end{array}$ & & \\
\hline 9 & $\begin{array}{l}\text { Intrumen yang } \\
\text { digunakan } \\
\text { membimbing } \\
\text { mahasiswa tentang } \\
\text { membuat } \\
\text { perencanaan (RPP), } \\
\text { melaksanakan } \\
\text { pembelajaran dan } \\
\text { melakukan evaluasi. }\end{array}$ & 4.69 & 0.468 \\
\hline 10 & $\begin{array}{l}\text { Panduan } \\
\text { microteaching ini } \\
\text { memberikan } \\
\text { kesempatan pada } \\
\text { mahasiswa untuk } \\
\text { melakukan refleksi. }\end{array}$ & 4.77 & 0.425 \\
\hline \multicolumn{2}{|c|}{ Keseluruhan Aspek Isi } & 4.61 & 0.488 \\
\hline \multicolumn{4}{|c|}{ ASPEK BAHASA } \\
\hline 1 & $\begin{array}{l}\text { Buku microteaching } \\
\text { dan panduannya } \\
\text { mudah dipahami }\end{array}$ & 4.69 & 0.468 \\
\hline 2 & $\begin{array}{l}\text { Buku microteaching } \\
\text { dan panduannya } \\
\text { menggunakan } \\
\text { informasi yang } \\
\text { mudah dimengerti. }\end{array}$ & 4.73 & 0.449 \\
\hline 3 & $\begin{array}{l}\text { Instrumen penilaian } \\
\text { pada tiap-tiap } \\
\text { keterampilan dasar } \\
\text { relevan untuk } \\
\text { menilai tiap-tiap } \\
\text { keterampilan dasar }\end{array}$ & 4.35 & 0.483 \\
\hline 4 & $\begin{array}{l}\text { Semua instrumen } \\
\text { yang digunakan } \\
\text { sesuai dengan } \\
\text { tujuan keterampilan } \\
\text { dasar mengajar. }\end{array}$ & 4.46 & 0.504 \\
\hline \multicolumn{2}{|c|}{ Kesluruan Aspek Bahasa } & 4.56 & 0.498 \\
\hline \multicolumn{2}{|c|}{ ASPEK ISI \& BAHASA } & 4.60 & 4.91 \\
\hline
\end{tabular}

Dari hasil analisis yang didapat pada Tabel 1 , rata-rata penilaian terhadap isi dari buku yaitu 4.61 dengan standar deviasi 0.488 . Sementara pada aspek bahasa diperoleh nilai rata-rata 4.56 dengan standar deviasi 0.498. Jika digabungkan, nilai rata-rata penilaian aspek isi dan bahasa yakni 4.60 dengan standar deviasi 4.91. Dengan nilai rata-rata 4.60 , mahasiswa dan dosen beranggapan bahwa buku microteaching berada pada kategori sangat baik.

Secara rinci, komentar mahasiswa tentang buku panduan microteaching dideskripsikan di Tabel 2.
Tabel 2: Komentar Mahasiswa tentang Buku Panduan Microteaching.

\begin{tabular}{|c|l|}
\hline No & $\begin{array}{l}\text { Komentar Mahasiswa tentang buku } \\
\text { panduan microteachng }\end{array}$ \\
\hline 1 & Sangat bermanfaat \\
\hline 2 & $\begin{array}{l}\text { Membantu sekali dalam membuat persiapan } \\
\text { mengajar }\end{array}$ \\
\hline 3 & $\begin{array}{l}\text { Sangat bagus merangsang proses } \\
\text { pembelajaran agar bisa mencetak guru } \\
\text { profesional }\end{array}$ \\
\hline 4 & Buku sangat menuntun mahasiswa \\
\hline 5 & $\begin{array}{l}\text { Membantu mahasiswa dalam merancang } \\
\text { pembelajaran dan memahami keterampilan } \\
\text { dasar mengajar sehingga mahasiswa lebih } \\
\text { siap mengajar }\end{array}$ \\
\hline 6 & $\begin{array}{l}\text { Membantu mahasiswa dalam memahami } \\
\text { komponen dalam mengajar }\end{array}$ \\
\hline 7 & $\begin{array}{l}\text { Mudah memahami dan membuat } \\
\text { mahasiswa mampu mengaplikasikan } \\
\text { keterampilan mengajar dengan baik }\end{array}$ \\
\hline 8 & $\begin{array}{l}\text { Sangat bermanfaat setiap komponennya } \\
\text { lengkap, mahasiswa mudah menerapkan } \\
\text { keterampilan-keterampilan dasar. }\end{array}$ \\
\hline 9 & $\begin{array}{l}\text { Sangat bermanfaat. Dari buku ini dapat } \\
\text { dipelajari bagaimana langkah-langkah } \\
\text { menjadi guru yang baik, dan keterampilan } \\
\text { dasaryang harus dipelajari. }\end{array}$ \\
\hline
\end{tabular}

Buku panduan seperti namanya memuat tentang langkah-langkah yang digunakan dalam pembelajaran microteaching. Buku panduan memuat semua instrumen asesmen yang dipakai dalam melaksanakan setiap tahapan pelaksanaan pembelajaran microteaching. Dengan buku ini, mahasiswa merasa sangat terbantu dan bisa memahami dengan mudah bagaimana semestinya pembelajaran microteaching dilakukan.

Untuk mendapatkan masukan yang lebih rinci tentang implementasi mata kuliah microteaching, mahasiswa juga menjawab kuesioner. Pada Tabel 3 berikut adalah data hasil analisis kuesioner penilaian mahasiswa terhadap implementasi Mata Kuliah Microteaching Pendidikan Bahasa Jepang. 
Tabel 3: Penilaian Mahasiswa Terhadap Implementasi Mata Kuliah Microteaching Pendidikan Bahasa Jepang.

\begin{tabular}{|c|c|c|c|}
\hline No & Pertanyaan & Mean & $\begin{array}{l}\text { Standard } \\
\text { Deviation }\end{array}$ \\
\hline 1 & $\begin{array}{l}\text { Dengan } \\
\text { microteaching saya } \\
\text { percaya saya } \\
\text { menjadi terampil } \\
\text { dalam mengajar. }\end{array}$ & 4.60 & 0.494 \\
\hline 2 & $\begin{array}{l}\text { Materi microteaching } \\
\text { yang dibuat sangat } \\
\text { bermakna bagi } \\
\text { mahasiswa yang } \\
\text { belajar microteaching. }\end{array}$ & 4.77 & 0.425 \\
\hline 3 & $\begin{array}{l}\text { Melalui } \\
\text { microteaching, } \\
\text { mahasiswa menjadi } \\
\text { yakin akan memiliki } \\
\text { keterampilan yang } \\
\text { memadai untuk } \\
\text { menjadi guru. }\end{array}$ & 4.90 & 0.309 \\
\hline 4 & $\begin{array}{l}\text { Dengan } \\
\text { microteaching } \\
\text { keterampilan dasar } \\
\text { menjadi guru bahasa } \\
\text { Jepang dinyatakan } \\
\text { berikut ini menjadi } \\
\text { meningkat. }\end{array}$ & 4.31 & 0.468 \\
\hline 5 & $\begin{array}{l}\text { Melalui } \\
\text { microteaching } \\
\text { keterampilan } \\
\text { mahasiswa untuk } \\
\text { mengajar inovatif } \\
\text { menjadi meningkat. }\end{array}$ & 4.21 & 0.410 \\
\hline 6 & $\begin{array}{l}\text { Microteaching juga } \\
\text { melatih mahasiswa } \\
\text { untuk membuat } \\
\text { persiapan mengajar } \\
\text { dengan baik dan } \\
\text { benar. }\end{array}$ & 4.40 & 0.494 \\
\hline 7 & $\begin{array}{l}\text { Microteaching juga } \\
\text { meningkatkan } \\
\text { kemampuan } \\
\text { mahasiswa calon } \\
\text { guru untuk menilai } \\
\text { pembelajaran. }\end{array}$ & 4.40 & 0.494 \\
\hline 8 & $\begin{array}{l}\text { Microteaching } \\
\text { meningkatkan } \\
\text { keterampilan } \\
\text { mahasiswa dalam } \\
\text { menyisip } \\
\text { pendidikan karakter } \\
\text { dan literasi dalam } \\
\text { pembelajaran. }\end{array}$ & 4.40 & 0.494 \\
\hline 9 & $\begin{array}{l}\text { Microteaching juga } \\
\text { meningkatkan } \\
\text { keterampilan } \\
\text { mahasiswa mencari }\end{array}$ & 4.31 & 0.468 \\
\hline
\end{tabular}

\begin{tabular}{|l|l|l|l|}
\hline $\begin{array}{l}\text { sumber materi } \\
\text { online }\end{array}$ & & \\
\hline Keseluruhan & $\mathbf{4 . 4 8}$ & $\mathbf{0 . 5 0 0}$ \\
\hline
\end{tabular}

Dari hasil analisis penilaian mahasiswa terhadap implementasi mata kuliah microteaching, diperoleh nilai rata-rata 4.48 dengan standard deviasi 500. Ini menunjukkan bahwa implementasi mata kuliah microteaching berada pada kategori baik.

Manfaat pembelajaran microteaching secara lebih rinci dinyatakan dalam Tabel 4.

Tabel 4: Respon mahasiswa terhadap manfaat pelaksanaan pembelajaran microteaching.

\begin{tabular}{|c|l|}
\hline No & $\begin{array}{l}\text { Respon mahasiswa terhadap manfaat } \\
\text { pelaksaan pembelajaran microteaching }\end{array}$ \\
\hline 1 & $\begin{array}{l}\text { Pelaksanaan microteaching menyiapkan } \\
\text { mental sebelum menjadi guru. }\end{array}$ \\
\hline 2 & $\begin{array}{l}\text { Microteaching melatih mahasiswa bisa } \\
\text { mengajar, menilai diri sendiri, dan } \\
\text { menyiapkan mental sebelum menjadi guru } \\
\text { yang professional. }\end{array}$ \\
\hline 3 & $\begin{array}{l}\text { Meningkatkan mental untuk menjadi guru } \\
\text { yang profesional. }\end{array}$ \\
\hline 4 & $\begin{array}{l}\text { Mahasiswa dapat belajar lebih awal tentang } \\
\text { berinterkasi langsung dengan siswa } \\
\text { meskipun dengan teman sekelas. Mahasiswa } \\
\text { mendapatkan gambaran tentang mengajar di } \\
\text { kelas, dapat belajar RPP dan media } \\
\text { pembelajaran, serta melatih kesiapan mental } \\
\text { untuk menjadi guru bahasa Jepang. }\end{array}$ \\
\hline 5 & $\begin{array}{l}\text { Bisa melatih menjadi seorang guru yang } \\
\text { profesional dan bertanggung jawab dengan } \\
\text { menerapkan keterampilan dasar mengajar, } \\
\text { serta bisa meningkatkan rasa percaya diri. } \\
\text { Mahasiswa paham komponen mengajar } \\
\text { seperti membuat RPP, memberi dan menilai } \\
\text { ujian dan sebagainya. }\end{array}$ \\
\hline 6 & $\begin{array}{l}\text { Memahami bagaimana cara mengajar dan } \\
\text { harus berani belajar dari kesalahan- } \\
\text { kesalahan lewat refleksi yang diberikan. }\end{array}$ \\
\hline 7 & $\begin{array}{l}\text { Menjadi tahu cara-cara mengajar yang baik, } \\
\text { mengenal berbagai metode dan strategi yang } \\
\text { dipakai dalam mengajar. }\end{array}$ \\
\hline 8 & $\begin{array}{l}\text { Dapat melatih diri tentang cara mengajar di } \\
\text { depan teman sekelas sebelum siap untuk } \\
\text { PPL Riil }\end{array}$ \\
\hline 9 & $\begin{array}{l}\text { Tahu bagaimana cara mengajar, percaya } \\
\text { diri, dan merasa siap mental untuk terjun ke } \\
\text { lapangan. }\end{array}$ \\
\hline 10 & $\begin{array}{l}\text { Belajar tentang cara mengajar terutama } \\
\text { memilih strategi mengajar. }\end{array}$ \\
\hline
\end{tabular}

Di samping itu, mahasiswa juga memberikan komentar tentang dampak pembelajaran microteaching terhadap keterampilan berbahasa Jepang mahasiswa. Dengan tuntutan simulasi pembelajaran bahasa 
Jepang, memberikan kesempatan kepada mahasiswa untuk meningkatkan keterampilan mereka berbahasa Jepang. Tabel 5 berikut menyajikan hasil tanggapan dari mahasiswa terkait pembelajaran microteaching.

Tabel 5: Tanggapan mahasiswa tentang dampak pembelajaran microteaching terhadap keterampilan berbahasa Jepang.

\begin{tabular}{|c|l|}
\hline No & \multicolumn{1}{|c|}{ Tanggapan } \\
\hline 1 & Meningkatkan keterampilan berbicara. \\
\hline 2 & Meningkatkan penguasaan kosa kata. \\
\hline 3 & Meningkatkan cara memberikan perintah. \\
\hline 4 & $\begin{array}{l}\text { Meningkatkan keterampilan berbahasa } \\
\text { Jepang. }\end{array}$ \\
\hline
\end{tabular}

Komentar yang diberikan pada Tabel 5 semua mahasiswa sependapat bahwa simulasi selama microteaching meningkatkan keterampilan berbahasa mereka, meskipun dalam kenyataannya (hasil observasi) mahasiswa sering merubah penjelasan ke dalam bahasa Indonesia ketika mereka sulit menjelaskan dalam bahasa Jepang.

Untuk mendapatkan data yang komprehensif, pengambilan data tentang implementasi microteaching juga dilakukan secara rinci pada setiap tahap. Tabel 6 berikut ini adalah hasil data yang diperoleh saat praktek pembelajaran mikro/microtecahing.

Tabel 6: Asesmen Diri untuk Menilai Persiapan Mengajar.

\begin{tabular}{|l|l|l|l|}
\hline No & \multicolumn{1}{|c|}{ Pernyataan } & Sudah & Belum \\
\hline 1 & $\begin{array}{l}\text { Saya sudah mengacu } \\
\text { pada silabus sebelum } \\
\text { RPP ini dibuat. }\end{array}$ & $100 \%$ & \\
\hline 2 & $\begin{array}{l}\text { Saya sudah } \\
\text { menggunakan format } \\
\text { RPP terbaru yang } \\
\text { berlaku di sekolah. }\end{array}$ & $100 \%$ & \\
\hline 3 & $\begin{array}{l}\text { Saya sudah } \\
\text { mengembangkan } \\
\text { pernyataan Kompetensi }\end{array}$ & $\begin{array}{l}\text { Inti dan Kompetensi } \\
\text { Dasar menjadi } \\
\text { indikator yang } \\
\text { operasional, yaitu yang } \\
\text { mengandung unsur- } \\
\text { unsur berikut: } \\
\text { A = Audience (jelas siapa } \\
\text { audien nya). } \\
\text { B = behavior (ada } \\
\text { perilaku jelas dan } \\
\text { dinyatakan dengan kata } \\
\text { kerja operasional). }\end{array}$ & \\
\hline
\end{tabular}

\begin{tabular}{|c|c|c|c|}
\hline & $\begin{array}{l}\mathrm{C}=\text { condition (jelas } \\
\text { kondisi yang } \\
\text { diinginkan). } \\
\mathrm{D}=\text { degree (jelas } \\
\text { tingkatan kompetensi } \\
\text { yang dingin dicapai). }\end{array}$ & & \\
\hline 4 & $\begin{array}{l}\text { Menggunakan } \\
\text { pernyataan tujuan yang } \\
\text { jelas. }\end{array}$ & $100 \%$ & \\
\hline 5 & $\begin{array}{l}\text { Materi relevan dan } \\
\text { sesuai dengan tingkat } \\
\text { perkembangan peserta } \\
\text { didik. }\end{array}$ & $100 \%$ & \\
\hline 6 & $\begin{array}{l}\text { Sudah memperhatikan } \\
\text { gerakan penguatan } \\
\text { pendidikan karakter, } \\
\text { keterampilan belajar } \\
\text { abad } 21 \text { dan "high order } \\
\text { thinking" siswa. }\end{array}$ & $42 \%$ & $58 \%$ \\
\hline 7 & $\begin{array}{l}\text { Jelas apa pendekatan } \\
\text { dan metode yang } \\
\text { dipakai. }\end{array}$ & $100 \%$ & \\
\hline 8 & $\begin{array}{l}\text { Jelas media dan alat } \\
\text { peraga yang digunakan. }\end{array}$ & $100 \%$ & \\
\hline \multirow[t]{8}{*}{9} & $\begin{array}{l}\text { Langkah-langkah } \\
\text { pembelajaran yang } \\
\text { digunakan: }\end{array}$ & & \\
\hline & $\begin{array}{l}\text { a. Jelas dan } \\
\text { mempermudah } \\
\text { pemahaman peserta } \\
\text { didik. }\end{array}$ & $100 \%$ & \\
\hline & b. Inovatif. & $80 \%$ & $20 \%$ \\
\hline & $\begin{array}{l}\text { c. Merangsang } \\
\text { pemikiran tingkat } \\
\text { tinggi. }\end{array}$ & $60 \%$ & $40 \%$ \\
\hline & $\begin{array}{l}\text { d. Memberikan } \\
\text { kesempatan peserta } \\
\text { didik untuk } \\
\text { mempraktekkan } \\
\text { penggunaan bahasa } \\
\text { asing yang dipelajari. }\end{array}$ & $100 \%$ & \\
\hline & $\begin{array}{l}\text { e. Menggunakan } \\
\text { pengelolaan kelas } \\
\text { yang efektif. }\end{array}$ & $100 \%$ & \\
\hline & $\begin{array}{l}\text { f. Memberi kesempatan } \\
\text { kepada peserta didik } \\
\text { untuk mengalami } \\
\text { sendiri dan } \\
\text { merumuskan } \\
\text { pengetahuan barunya } \\
\text { berdasarkan } \\
\text { pengalaman tersebut. }\end{array}$ & $100 \%$ & \\
\hline & g. Menarik. & $80 \%$ & $20 \%$ \\
\hline \multirow[t]{4}{*}{10} & Asesmen & & \\
\hline & $\begin{array}{l}\text { a. Menilai sesuai } \\
\text { dengan materi yang } \\
\text { diajarkan. }\end{array}$ & $100 \%$ & \\
\hline & b. Relevan. & $100 \%$ & \\
\hline & c. Otentik. & $100 \%$ & \\
\hline
\end{tabular}




\begin{tabular}{|l|l|c|c|}
\hline & $\begin{array}{l}\text { d. Sesuai dengan } \\
\text { indikator . }\end{array}$ & $100 \%$ & \\
\hline & e. Disertai contoh. & $80 \%$ & $20 \%$ \\
\hline & f. Ada rubrik penilaian. & $100 \%$ & \\
\hline 11 & Penutup & & \\
\hline & $\begin{array}{l}\text { a. Membimbing peserta } \\
\text { didik untuk } \\
\text { merangkum materi } \\
\text { yang diajar. }\end{array}$ & $100 \%$ & \\
\hline & $\begin{array}{l}\text { b. Ada kegiatan } \\
\text { penutup }\end{array}$ & $100 \%$ & \\
\hline
\end{tabular}

Persepsi mahasiswa tentang simulasi praktek mengajar, diawali dengan penilaian diri terhadap persiapan mengajar yang dikerjakan oleh mahasiswa. Berdasarkan hasil asesmen diri, dapat diketahui bahwa ada beberapa point dari penilaian tersebut yang diyakini belum dipenuhi oleh mahasiswa. Misalnya $58 \%$ dari peserta (28 orang dari 48 mahasiswa) merasa bahwa mereka belum mampu mengakomodasi gerakan penguatan pendidikan karakter, keterampilan belajar abad 21 dan "high order thinking" siswa dalam persiapan mengajar mereka. Sekitar 20\% mahasiswa juga merasa belum inovatif.

Karena proses pembuatan RPP dilakukan di luar jam pelajaran, maka sulit bagi dosen pengajar untuk mengontrol mahasiswa. Oleh sebab itu, sebagai bahan refleksi bagi mahasiswa dan dosen, maka instrumen 2 tentang asesmen diri untuk menilai proses pembuatan RPP bisa diberikan kepada mahasiswa. Tabel 7 menyatakan hasil asesmen diri untuk menilai proses pembuatan RPP.

Hasil kuesioner asesmen diri tentang persiapan membuat RPP dapat dinyatakan bahwa mahasiswa belum terbiasa mencari materi online karena sekitar 20 orang dari 48 mahasiswa menjawab 'tidak' pada pernyataan no 2. Dengan kata lain sekitar 28 dari 48 mahasiswa merasa terampil mencari materi online. Hasil wawancara memperjelas pernyataan 20 mahasiswa tersebut, dimana mereka merasa terlalu sombong jika menjawab dengan 'ya' karena meskipun mereka sudah sering mencari materi online, mereka belum berani mengatakan diri 'terampil'. Hal yang menarik adalah pendapat mereka tentang membuat persiapan, 43 orang dari 48 mahasiswa menyatakan pembuatan RPP tidak efisien karena RPP yang mereka buat yaitu RPP format sekolah sesuai dengan kurikulum 2013. Menurut mereka RPP bisa dibuat lebih sederhana dan singkat.
Tabel 7: Asesmen Diri untuk Menilai Proses Persiapan (Pembuatan RPP).

\begin{tabular}{|c|l|c|c|}
\hline $\begin{array}{c}\mathrm{N} \\
\mathrm{O}\end{array}$ & \multicolumn{1}{|c|}{ Pernyataan } & Ya & Tidak \\
\hline 1 & $\begin{array}{l}\text { Waktu yang tersedia untuk } \\
\text { mengerjakan persiapan } \\
\text { mengajar cukup. }\end{array}$ & $80 \%$ & $20 \%$ \\
\hline 2 & $\begin{array}{l}\text { Saya terampil mencari materi } \\
\text { secara online. }\end{array}$ & $58 \%$ & $42 \%$ \\
\hline 3 & $\begin{array}{l}\text { Saya banyak menemukan situs } \\
\text { yang relevan untuk } \\
\text { mengembangan materi untuk } \\
\text { bahan ajar saya. }\end{array}$ & $\begin{array}{l}\text { Diantaranya adalah (tulis contoh } \\
\text { situs yang sudah Anda coba): } \\
\text { a. https://www.nhk.or.jp } \\
\text { b. https://siriushades.wordpres } \\
\text { s. com }\end{array}$ & $21 \%$ \\
$\begin{array}{l}\text { c. https://kelaskita.com } \\
\text { d. http://erlangga.co.id/compo } \\
\text { nent/content/article9579.ht } \\
\text { ml. }\end{array}$ & $\begin{array}{l}\text { e. http://erlangga.co.id/compo } \\
\text { nent/content/article9578.ht } \\
\text { ml. } \\
\text { f. http://erlangga.co.id/compo } \\
\text { nent/content/article9577.ht } \\
\text { ml. }\end{array}$ & $\begin{array}{l}\text { Bagi saya membuat persiapan } \\
\text { dalam kelompok lebih baik dari } \\
\text { bekerja sendiri. }\end{array}$ & $40 \%$ \\
\hline 5 & $\begin{array}{l}\text { Saya tidak mengalami masalah } \\
\text { dalam membuat persiapan }\end{array}$ & $58 \%$ \\
\hline 6 & $\begin{array}{l}\text { Bagi saya membuat persiapan } \\
\text { ini tidak efisien. }\end{array}$ & $10,4 \%$ & $89,6 \%$ \\
\hline
\end{tabular}

Keterampilan menjelaskan merupakan keterampilan yang memegang peranan sangat penting bagi calon guru Bahasa Jepang karena kejelasan informasi yang disampaikan sangat tergantung pada kualitas bahasa Jepang dari calon guru. Dari hasil penilaian asesmen sejawat yang tersaji pada tabel 8, dapat diketahui bahwa 60\% (29 dari 48 mahasiswa) menyatakan bahwa mahasiswa calon guru kadang-kadang menggunakan variasi dalam menjelaskan sehingga kelas menjadi hidup dan menarik. Dengan kata lain, simulasi yang dilakukan mahasiswa tidak selalu menarik. Demikian juga halnya dengan strategi menjelaskan memotivasi peserta didik untuk bertanya dan berpikir kritis dimana 60\% menjawab 'kadang-kadang'. Dengan kata lain kedua hal tersebut, menurut mahasiswa, masih harus ditingkatkan. 
Tabel 8: Penilaian Asesmen Sejawat: Keterampilan Menjelaskan.

\begin{tabular}{|c|c|c|c|c|}
\hline $\begin{array}{l}\mathrm{N} \\
\mathrm{O}\end{array}$ & Pernyataan & Ya & Kadang & Tidak \\
\hline 1 & $\begin{array}{l}\text { MCG memahami apa } \\
\text { yang dijelaskannya. }\end{array}$ & $\begin{array}{l}100 \\
\%\end{array}$ & & \\
\hline 2 & $\begin{array}{l}\text { MCG } \\
\text { mendeskripsikan topik } \\
\text { dengan tepat. }\end{array}$ & $\begin{array}{l}100 \\
\%\end{array}$ & & \\
\hline 3 & $\begin{array}{l}\text { MCG menjelaskan } \\
\text { konsep dengan } \\
\text { menggunakan langkah- } \\
\text { langkah yang mudah } \\
\text { dipahami. }\end{array}$ & $\begin{array}{l}100 \\
\%\end{array}$ & & \\
\hline 4 & $\begin{array}{l}\text { Strategi menjelaskan } \\
\text { yang digunakan MCG } \\
\text { dalam melaksanakan } \\
\text { pembelajaran bagus } \\
\text { dan bermakna. }\end{array}$ & $80 \%$ & $20 \%$ & \\
\hline 5 & $\begin{array}{l}\text { MCG menggunakan } \\
\text { variasi dalam } \\
\text { menjelaskan sehingga } \\
\text { kelas menjadi hidup } \\
\text { dan menarik. }\end{array}$ & $40 \%$ & $60 \%$ & \\
\hline 6 & $\begin{array}{lr}\text { Gestur/gerak tubuh } \\
\text { dan ekspresi yang } \\
\text { digunakan MCG tepat. }\end{array}$ & $80 \%$ & $20 \%$ & \\
\hline 7 & $\begin{array}{lr}\text { Struktur ide yang } \\
\text { disampaikan } \\
\text { jelas. }\end{array}$ & $\begin{array}{l}100 \\
\%\end{array}$ & & \\
\hline 8 & $\begin{array}{l}\text { Pengelolaan waktu } \\
\text { yang digunakan } \\
\text { pembicara akurat. }\end{array}$ & $\begin{array}{l}100 \\
\%\end{array}$ & & \\
\hline 9 & $\begin{array}{l}\text { Saya pikir saya mampu } \\
\text { lebih baik dari MCG. }\end{array}$ & & $100 \%$ & \\
\hline 10 & $\begin{array}{l}\text { Strategi menjelaskan } \\
\text { memotivasi peserta } \\
\text { didik untuk bertanya } \\
\text { dan berpikir kritis. }\end{array}$ & $40 \%$ & $60 \%$ & \\
\hline
\end{tabular}

Untuk meningkatkan keterampilan menjelaskan, Tabel 9 menjelaskan tentang halhal yang dilakukan mahasiswa untuk meningkatkan keterampilan menjelaskan.

Tabel 9: Asesmen diri untuk meningkatkan keterampilan menjelaskan.

\begin{tabular}{|c|l|l|l|l|l|l|}
\hline $\mathrm{N}$ & \multicolumn{1}{|c|}{ Pertanyaan } & \multicolumn{4}{|c|}{ Penilaian (n=48 orang) } \\
\cline { 3 - 7 } $\mathrm{o}$ & & 4 & 3 & 2 & 1 & 0 \\
\hline 1 & $\begin{array}{l}\text { Saya mempraktekkan } \\
\text { bahasa asing yang saya } \\
\text { pelajari selama 30 } \\
\text { menit setiap hari agar } \\
\text { keterampilan } \\
\text { menjelaskan saya } \\
\text { meningkat. }\end{array}$ & $10 \%$ & $90 \%$ & & \\
\hline 2 & $\begin{array}{l}\text { Saya membaca buku } \\
\text { atau artikel dalam } \\
\text { bahasa asing yang saya }\end{array}$ & & $20 \%$ & $80 \%$ & & \\
\hline
\end{tabular}

\begin{tabular}{|c|l|l|l|l|l|l|}
\hline & $\begin{array}{l}\text { pelajari untuk } \\
\text { meningkatkan } \\
\text { pembendaharaan kosa } \\
\text { kata saya. }\end{array}$ & & & & & \\
\hline 3 & $\begin{array}{l}\text { Saya suka } \\
\text { mengerjakan kegiatan } \\
\text { mandiri untuk } \\
\text { mempraktekkan } \\
\text { bahasa asing yang saya } \\
\text { pelajari tanpa disuruh } \\
\text { guru. }\end{array}$ & & $40 \%$ & $60 \%$ & & \\
\hline 4 & $\begin{array}{l}\text { Saya suka menonton } \\
\text { siaran dalam bahasa } \\
\text { asing yang saya } \\
\text { pelajari untuk } \\
\text { menambah wawasan } \\
\text { budaya bahasa target. }\end{array}$ & & $20 \%$ & $80 \%$ & & \\
\hline 5 & $\begin{array}{l}\text { Saya suka menjalin } \\
\text { komunikasi dengan } \\
\text { penutur asli bahasa } \\
\text { asing yang saya } \\
\text { pelajari. }\end{array}$ & 80 & $20 \%$ & & & \\
\hline
\end{tabular}

4=sering, 3=biasanya, 2=kadang-kadang, 1=jarang, $0=$ tidak pernah

Dari semua strategi yang dinyatakan, menjalin komunikasi dengan penutur asli dianggap paling sering dilakukan oleh mahasiswa. Hal ini bisa dimaklumi karena ketersediaan sukarelawan penutur asli sangat membantu mahasiswa dalam berkomunikasi dalam bahasa Jepang.

Keterampilan-keterampilan dasar yang dipraktekkan oleh mahasiswa secara implisit memberdayakan keterampilan 5C mahasiswa baik itu di bidang communication (komunikasi), collaboration (Kolaborasi), creativity (kreativitas) critical thinking (pemikiran kritis), dan character (karakter). Keterampilan menjelaskan merupakan salah satu keterampilan dasar yang mendidik mahasiswa calon guru untuk mampu mengkomunikasikan ide agar konsep mudah dipahami siswa. Kolaborasi selalu dilatih baik dalam tahapan persiapan maupun dalam praktek simulasi. Mahasiswa ditugaskan kerja kelompok dalam mencari materi online, kemudian dalam simulasi selama praktikum di kelas mereka saling memberikan input dan masukan untuk perbaikan. Kreativitas sangat ditekankan oleh dosen pengajar baik itu dalam mengembangkan media, memilih strategi mengajar maupun dalam memilih permainan dan lagu. Pemikiran kritis mahasiswa dilatih saat diskusi maupun saat memberikan penilaian sejawat agar mampu memperbaiki kelemahan dalam simulasi mengajar. Pendidikan karakter selalu ditekankan sejak awal perkuliahan dan 
merupakan kebijakan lembaga sejak beberapa tahun sebelumnya.

\section{Pembahasan}

Hasil analisis data tentang persepsi mahasiswa bisa dinyatakan secara umum bahwa mahasiswa memiliki persepsi yang positif tentang pelaksanaan pembelajaran microteaching di Jurusan Pendidikan Bahasa Jepang, Undiksha. Penggunaan buku ajar microteaching dirasakan sangat memberikan manfaat karena mahasiswa memiliki buku pegangan yang bisa dipakai sebagai acuan untuk memahami konsep dasar tentang microteaching. Hal ini terlihat dari penilaian mahasiswa terhadap buku ajar tersebut yaitu sangat baik. Pandangan mahasiswa juga memperjelas bahwa konsep yang ditulis dalam buku ajar sangat bermanfaat disamping penggunaan bahasa pengantar dinilai mudah untuk dipahami.

Tanggapan mahasiswa ini sangat penting karena buku ajar microteaching merupakan sumber utama yang digunakan dalam pembelajaran microteaching yang mempunyai peran penting dalam pengenalan konsep microteaching dan keterampilan dasar mengajar yang harus dikuasi mahasiswa. Di samping itu, kejelasan dan kemudahan bahasa pengantar buku ajar juga penting untuk diperhatikan agar mahasiswa membaca buku dengan nyaman dan mudah mencerna maknanya.

Penguasaan konsep dasar microteaching dan keterampilan dasarnya merupakan fondasi dasar agar mereka mampu mempraktekkan tiap-tiap keterampilan dasar untuk mengajarkan topik/tema tertentu. Dalam membuat perencanaan pembelajaran (RPP) mahasiswa merasakan bahwa pembelajaran microteaching melatih mereka membuat perencanaan menjadi lebih baik. Hal ini sejalan dengan apa yang dikatakan Bell (2007) bahwa pembelajaran microteaching tidak saja meningkatkan keterampilan praktek mengajar mahasiswa tetapi juga dalam membuat perencanaan.

Dalam pembuatan perencanaan pembelajaran, sebagian besar mahasiswa merasa bahwa pembuatan RPP tersebut tidak efisien, disebabkan banyaknya poin yang harus dimasukkan. Mereka beranggapan bahwa RPP bisa dibuat lebih sederhana. Hal ini tentunya bukan menjadi kendala lagi pada pembelajaran sekarang, dimana terdapat perubahan dalam pembuatan RPP yang dituntut oleh pemerintah yaitu hanya satu halaman.
Selain hal di atas, dalam usaha meningkatkan keterampilan mahasiswa dalam membuat perencanaan, terdapat beberapa poin yang masih menjadi kendala bagi mahasiswa. Menurut mahasiswa hal yang belum mereka kuasai yaitu keterampilan abad 21, mengakomodasi keterampilan berpikir tingkat tinggi dan inovatif dalam perencanaan pembelajaran. Ketiga hal tersebut merupakan bagian dari implementasi kurikulum 2013. Dalam lampiran Peraturan Menteri Pendidikan dan Kebudayaan No 70/Tahun 2013 tentang Kerangka Dasar dan Struktur Kurikulum Sekolah Menengah Kejuruan/Madrasah Aliyah Kejuruan dinyatakan bahwa pengembangan Kurikulum 2013 dilandasi oleh adanya tantangan eksternal dengan adanya arus globalisasi. Dengan fenomena ini, maka keterampilan abad 21 yang diantaranya menyangkut keterampilan belajar dan inovasi (yang sering disingkat $4 \mathrm{C}$ yaitu creativity, critical thinking, communication and collaboration) oleh Trilling dan Fadel (2009) sangat mutlak harus dikuasai. Beberapa mahasiswa merasa belum percaya diri tentang strategi memasukkan keterampilan abad 21, dimana masalah ini menjadi masukan bagi dosen pengampu mata kuliah untuk lebih menekankan dalam perkuliahan. Di samping hal itu, keterampilan dalam mengakomodasi keterampilan berpikir tingkat tinggi juga dirasakan sebagai keterampilan yang sulit bagi mahasiswa. Saran yang diberikan oleh dosen pembimbing adalah meningkatkan rasa ingin tahu mahasiswa dengan melatih mereka meningkatkan keterampilan bertanya. Keterampilan bertanya merupakan keterampilan yang sangat perlu untuk dilatih (Shah \& Masrur, 2011; Remesh, 2013; Ghafoor dkk, 2012; Saban \& Çoklar, 2013 dalam Padmadewi, Artini \& Agustini, 2017) dinyatakan bahwa keterampilan bertanya dibedakan menjadi dua yaitu keterampilan bertanya dasar dan keterampilan bertanya lanjut. Dalam konteks melatih keterampilan berpikir tingkat tinggi, maka mahasiswa calon guru bisa mendidik siswa untuk bertanya mulai dari bertanya dasar, dan jika bertanya dasar sudah terampil, maka mereka bisa dilatih untuk bertanya tingkat lanjut. Bertanya tingkat lanjut meliputi beberapa keterampilan yaitu keterampilan mengubah pertanyaan untuk merangsang pemikiran kritis, menggunakan pertanyaan secara implisit untuk menggali jawaban divergen dan kompleks, dan memberikan urutan pertanyaan yang 
membimbing dan merangsang jawaban, serta membantu peserta didik. Hal ini dianggap sulit oleh beberapa mahasiswa sehingga pada saat simulasi banyak mahasiswa menggunakan bahasa Indonesia ketika mereka menggunakan keterampilan bertanya lanjut.

Pitoy (2012) menyatakan bahwa memahami informasi secara rinci adalah kunci untuk bisa berbagi informasi. Oleh sebab itu, keterampilan dalam bahasa asing sangat dibutuhkan agar calon guru bisa berbagi informasi kepada siswa secara benar. Sehubungan dengan hal ini, persepsi mahasiswa tentang keterampilan menjelaskan sangat perlu dicermati. Tabel 8 menjelaskan hasil penilaian teman sejawat tentang keterampilan menjelaskan. Dari hasil tersebut ternyata mahasiswa merasa bahwa beberapa mahasiswa kadang-kadang belum menjelaskan dengan baik. Hal yang menarik adalah semua mahasiswa merasa bahwa mareka bisa menjelaskan lebih baik dari temannya. Kepercayaan diri tinggi ini dianggap sangat positif agar mahasiswa calon guru yakin bisa meningkatkan diri lebih baik dari teman sejawatnya.

Tabel 9 menggali kegiatan yang dilakukan mahasiswa tentang strategi belajar untuk meningkatkan keterampilan menjelaskan mereka. Hal ini sangat perlu bagi dosen pengampu agar memudahkan memberi saran sesuai dengan apa yang disenangi oleh mahasiswa. Dari Tabel 9 bisa diketahui bahwa mahasiswa menggunakan berbagai strategi untuk meningkatkan keterampilan menjelaskan yaitu dengan menggunakan media, serta beragam cara yang digunakan untuk melatih keterampilan berbahasa mereka. Strategi yang paling sering digunakan oleh mahasiswa dalam meningkatkan keterampilan menjelaskan adalah menjalin komunikasi dengan penutur bahasa Jepang.

Di samping keterampilan menjelaskan secara umum, mahasiswa memberikan tanggapan bahwa implementasi pembelajaran microteaching bermanfaat dalam meningkatkan keterampilan mereka mengajar, hal ini diperkuat oleh data kuisioner menunjukkan hasil dengan kategori baik. Hal ini mengkonfirmasi penelitian-penelitian sebelumnya (Fernandez \& Robinson, 2006; Kilic, 2010; Ismail, 2011; Donnelly \& Fitzmaurice, 2011; Anthonia, 2014; Astika, 2014). Penggunaan asesmen diri dan asesmen sejawat sangat penting dalam pembelajaran microteaching. Tetapi pada kenyataannya, diskusi dengan teman sejawat dan asesmen teman sejawat sangat jarang terjadi bahkan hanya dilakukan sekali atau dua kali setahun (Tiknaz \& Sutton, 2006). Dengan demikian diharapkan studi ini bisa mengkonfirmasi perlunya asesmen diri dan asesmen sejawat untuk mendapatkan refleksi bagi mahasiswa dalam upaya meningkatkan keterampilan mereka mengajar.

Diharapkan persepsi mahasiswa dalam kajian ini bisa menginspirasi para dosen microteaching terutama dalam pembelajaran bahasa asing untuk memahami kondisi riil mahasiswa sehingga bisa membantu mereka menjadi lebih terampil dalam mengajar bahasa asing. Meskipun penelitian ini memberikan tanggapan yang positif, perlu penelitian lebih lanjut apakah persepsi mahasiswa berkorelasi dengan keterampilan mereka mengajar, yang bisa menjadi rekomendasi untuk penelitian lebih lanjut di waktu mendatang.

\section{KESIMPULAN DAN SARAN}

Pembelajaran microteaching sangat penting dalam membentuk keterampilan guru mengajar. Microteaching merupakan muara pertemuan teori dan praktek. Pembelajaran microteaching menuntut calon guru untuk mampu mempraktekkan teori keguruan yang dipelajari baik itu dalam merencanakan pembelajaran, melaksanakan pembelajaran maupun untuk melaksanakan asesmen. Mempraktekkan tiaptiap keterampilan dasar perlu mendapat input tidak saja dari dosen pengajar tetapi juga dari mahasiswa sendiri maupun dari teman sejawat. Tanggapan yang diberikan oleh mahasiswa memberikan informasi dari perspektif mahasiswa yang sangat penting untuk diperhatikan dan dicermati agar dosen pengampu mata kuliah microteaching bisa memberikan masukan tepat sasaran sesuai dengan situasi dan kondisi mahasiswa. Persepsi yang diberikan mahasiswa merupakan kondisi nyata tentang kondisi mahasiswa itu sendiri yang sering diabaikan oleh dosen pengampu. Diharapkan hasil penelitian ini bisa memberikan masukan kepada dosen microteaching tidak hanya untuk pendidikan bahasa Jepang tetapi juga untuk pendidikan bahasa asing lainnya. 


\section{UCAPAN TERIMA KASIH}

Penelitian ini dapat terselenggara dengan bantuan dana DRPM Dikti, serta kerjasama dari pengajar serta mahasiswa.

\section{DAFTAR PUSTAKA}

Anthonia, O.I. (2014). Microteaching: a technique for effective teaching. African Research Review. An International Multidisciplinary Journal, Ethiopia.8(4), 183-197.

Astika, G. (2014). Reflective teaching as alternative assessment in teacher education: a case study of pre-service teachers. TEFLIN Journal, 25(1).

Bell, N. D. (2007). Microteaching: what is it that is going on here? Linguistics and Education, 18(1), 24-40.

Bello, A.O., \& Ayelaagbe, S.O. (2015). Microteaching: a strategy for training quality teachers in Nigerian Colleges of Education. Journal of Qualitative Education, 11(1), 1-8.

Creswell, J. W. (2009). Research Design: Qualitative, Quantitative, and Mixed Methods Approaches. Los Angeles: Sage.

Donnelly, R., \& Fitzmaurice, M. (2011). Towards productive reflective practice in microteaching. Innovations in Education and Teaching International, 48(3), 335-346.

Fernandez, M. L. (2005). Learning through microteaching lesson study in teacher preparation. Action in Teacher Education, 26, 3747.

https://doi.org/10.1080/01626620.2005.10463 341

Fernandez, M., \& Robinson, M. (2006). Prospective teachers' perspectives on microteaching lesson study. Education, 127(2), 203-215.

Ghafoor, A., Kiani, A., \& Kayani, S. (2012). An exploratory study of microteaching as an effective technology. International Journal of Bussiness and Social Science, 3(4). Diakses dari www.ijbssnet.com.

Ghanaguru, S., Nair, P., \& Yong, C. (2013). Teacher trainers' beliefs in microteaching and lesson planning in a teacher training institution. The English Teacher, 42(2).

Ismail, S. A. A. (2011). Student teachers' microteaching experiences in pre-service English Teacher Education Program. Journal of Language Teaching and Research, 2(5), 1043-1051. https://doi.org/10.4304/jltr.2.5.1043_1051

Kilic, A. (2010). Learner-centered microteaching in teacher education. International Journal of Instruction, 3(1). Diakses dari www.e.iji.net.

Kpanja, E. (2001). A study of the effects of video tape recording in microteaching training. British Journal of Educational Technology, 32(4), 483-486. http://dx.doi.org/10.1016/j.sbspro.2012.05.28 8

Kumar, S. (2016). Microteaching "an efficient technique for learning effective teaching" International Journal of Research in IT and Management (IJRIM), 6(8), 51-61.

Ping, W. (2013). Microteaching: a powerful tool to embedding the English teacher certification testing in the development of English teaching methodologies. International Journal of English Language and Literature Studies, 2(3), 163-175. Retrieved

from http://www.aessweb.com/journaldetail.php?id=5019.

Pitoy, S. P. (2012). Information and language for communicative communication. TEFLIN Journal, 23(1). http://dx.doi.org/10.15639/teflinjournal.v23i1 /91-114

Padmadewi, N. N., Artini, L. P., \& Agustini, D. A. E. (2017). Pengantar Microteaching. Depok: Raja Grapindo Persada.

Padmadewi, N.M., \& Mardani, D. S. M. (2017). Penyesuaian model pembelajaran mata kuliah microteaching berbasis standar proses kurikulum 2013 untuk lptk penyelenggara pendidikan bahasa Jepang di bali (Laporan Hasil Penelitian tidak dipublikasikan).

Partnership for advance Clinical Education (PACE). Microteaching. Diakses dari: Microteaching(PACE).pdfchs.uonbi.ac.ke/sites/default/files /chs/chs/Microteaching-(PACE).pdf.

Peraturan Menteri Pendidikan Dan Kebudayaan Republik Indonesia Nomor 81a Tahun 2013 tentang Implementasi Kurikulum.

Peraturan Menteri Pendidikan Dan Kebudayaan Republik Indonesia Nomor 160 Tahun 2014 tentang Pemberlakuan Kurikulum 2006 dan Kurikulum 2013.

Peraturan Menteri Pendidikan Dan Kebudayaan Republik Indonesia Nomor 103 Tahun 2014 tentang Pembelajaran pada Pendidikan Dasar dan Pendidikan Menengah.

Peraturan Menteri Pendidikan Dan Kebudayaan Republik Indonesia Nomor 104 Tahun 2014 tentang Penilaian Hasil Belajar oleh Pendidik pada Pendidikan Dasar dan Pendidikan Menengah

Peraturan Menteri Pendidikan Dan Kebudayaan Republik Indonesia Nomor No 70 / Tahun 2013 Kerangka Dasar dan Struktur Kurikulum Sekolah Menengah Kejuruan/ Madrasah Aliyah Kejuruan.

Remesh, A. (2013). Microteaching an effective teachnique for learning effective teaching. Journal of Research in Medical Science, 18(2), 158163. Diakses dari www.ncbi.nlm.nih.gov.

Saban, A., \& Çoklar, A. N. (2013). Pre-service teachers' opinions about the microteaching method in teaching practice classes. TOJET. The Turkish Online Journal of Educational Technology, 
12(2), 234-240. Diakses dari http://files.eric.ed.gov/fulltext/EJ1015454.pdf

Shah, S. M. H., \& Masrur, R. (2011). Impact of microteaching skills on the performance of primary school teachers. Gomal University Journal of Research, 27(1), 15-29. Diakses dari http://www.gomal.pk/GUJR/PDF/PDF-

June-2011/3\%20Manzoor\%201529\%20Paper.pdf.

Tiknaz, Y., \& Sutton, A. (2006). Exploring the role of assessment tasks to promote formative assessment in Key Stage 3 Geography: evidence from twelve teachers. Assessment in Education
13(3),

$327-343$

https://doi.org/10.1080/09695940601035502

Trilling, B., \& Fadel, C. (2009). 21 $1^{\text {st }}$ Century Skills: Learning for Life in our Time. San Francisco: Jossey-Bass.

Centre for Teaching and Learning Harvard University. (1999). What is Microteaching? Diakses dari isite.harvard.edu/fs/html/icb.topic58474/micr oteaching.html.

Teaching Support Services. Diakses dari www.tss.uoguelph.ca. 